University of Nebraska - Lincoln

DigitalCommons@University of Nebraska - Lincoln

Faculty Publications from Nebraska Center for

Materials and Nanoscience, Nebraska Center Materials and Nanoscience

for (NCMN)

2-1-1992

\title{
Icosahedral phase stabilities in Al-Cu-Ru alloys
}

Jeffrey E. Shield

University of Nebraska - Lincoln, jshield@unl.edu

C. Hoppe

Ames Laboratory, lowa State University, Ames, lowa

R.W. McCallum

Ames Laboratory, lowa State University, Ames, lowa

A.I. Goldman

Ames Laboratory, lowa State University, Ames, lowa

K.F. Kelton

Washington University, St. Louis, Missouri

See next page for additional authors

Follow this and additional works at: https://digitalcommons.unl.edu/cmrafacpub

Part of the Nanoscience and Nanotechnology Commons

Shield, Jeffrey E.; Hoppe, C.; McCallum, R.W.; Goldman, A.I.; Kelton, K.F.; and Gibbons, P.C., "Icosahedral phase stabilities in Al-Cu-Ru alloys" (1992). Faculty Publications from Nebraska Center for Materials and Nanoscience. 49.

https://digitalcommons.unl.edu/cmrafacpub/49

This Article is brought to you for free and open access by the Materials and Nanoscience, Nebraska Center for (NCMN) at DigitalCommons@University of Nebraska - Lincoln. It has been accepted for inclusion in Faculty Publications from Nebraska Center for Materials and Nanoscience by an authorized administrator of DigitalCommons@University of Nebraska - Lincoln. 


\section{Authors}

Jeffrey E. Shield, C. Hoppe, R.W. McCallum, A.I. Goldman, K.F. Kelton, and P.C. Gibbons 


\title{
Icosahedral phase stabilities in Al-Cu-Ru alloys
}

\author{
J. E. Shield, ${ }^{*}$ C. Hoppe, R. W. McCallum, ${ }^{*}$ and A. I. Goldman ${ }^{\dagger}$ \\ Ames Laboratory, Iowa State University, Ames, Iowa 50011 \\ K. F. Kelton and P. C. Gibbons \\ Department of Physics, Washington University, St. Louis, Missouri 63130
}

(Received 31 July 1991)

\begin{abstract}
By examining a wide region of the Al-Cu-Ru phase diagram, a thorough analysis of the compositional and thermal stability of the icosahedral phase has been completed. The primary solidification product of rapid solidification was a topologically and chemically disordered icosahedral phase with an extensive compositional region. Crystallization through exothermic events of the as-solidified materials produced crystalline phases, without the formation of the face-centered-icosahedral (FCI) phase. However, the FCI phase does form at higher temperatures through an endothermic reaction, indicating that it is a stable phase of the system, but only at elevated temperatures. Of the alloys studied, the FCI phase field was found to encompass $\mathrm{Al}_{65} \mathrm{Cu}_{23} \mathrm{Ru}_{12}, \mathrm{Al}_{65} \mathrm{Cu}_{20} \mathrm{Ru}_{15}, \mathrm{Al}_{70} \mathrm{Cu}_{20} \mathrm{Ru}_{10}$, and $\mathrm{Al}_{70} \mathrm{Cu}_{15} \mathrm{Ru}_{15}$. The transformation to the FCI phase involves an intermediate approximant phase that is very similar to the FCI structure. Also, a cubic approximant containing atomic arrangements with local icosahedral symmetry similar to $\alpha-\mathrm{Al} \mathrm{Mn}$ Si was determined to exist near the FCI phase field.
\end{abstract}

\section{INTRODUCTION}

The discovery of a class of materials with long-range icosahedral point-group symmetry ${ }^{1}$ has opened further avenues of research in crystallography, chemistry, physics, and materials science. The determination of phase equilibria in these quasicrystalline materials can provide useful information about the conditions favorable to their formation as well as their structure. Clues are provided to the chemical makeup and the energetics involved in stabilizing the structure simply by determining the range, in both temperature and composition, over which icosahedral alloys form. Details of the atomic structure of the icosahedral phase can be deduced from nearby crystalline phases with local icosahedral symmetry. Many quasicrystalline alloy systems are known to contain these "approximant" phases, such as, Al-Mn-Si, ${ }^{2} \mathrm{Al}-\mathrm{Li}$ $\mathrm{Cu},{ }^{3}$ and $\mathrm{Ti}-\mathrm{Mn}-\mathrm{Si}^{4}{ }^{4}$

The thermal stability of the face-centered icosahedral (FCI) alloys $\mathrm{Al}-\mathrm{Cu}-\mathrm{Fe}$ and $\mathrm{Al}-\mathrm{Cu}-\mathrm{Ru}$ has received much attention recently. These alloys differ from the previously known simple icosahedral (SI) alloys in their enhanced degree of chemical and topological order. For instance, the FCI alloys exhibit resolution-limited x-ray-diffraction peak widths, ${ }^{5}$ and, therefore, lack the peculiar "phason strain" that is inherent to SI alloys. ${ }^{6}$ These alloys have also focused attention on two competing theoretical mod$\mathrm{els}^{7,8}$ for the structure of equilibrium quasicrystalline alloys, for which the thermal stability is a major discriminating factor. The phase diagrams of these systems would thus provide useful information on the most correct description, while also providing fundamental understanding of these alloys from a materials-science perspective.

The Al-Cu-Fe phase diagram was first investigated many years before the discovery of icosahedral alloys. ${ }^{9}$
The compositional stability of the FCI phase and its equilibrium with respect to neighboring phases has recently been extensively investigated at temperatures above $680^{\circ} \mathrm{C}{ }^{10}$ The thermal stability of the FCI phase has also received much attention. Many experimental results support the existence of a crystalline approximant phase at lower temperatures at some compositions. For example, $\mathrm{x}$-ray powder diffraction patterns of $\mathrm{Al}_{65} \mathrm{Cu}_{23} \mathrm{Fe}_{12}$ samples annealed below $670^{\circ} \mathrm{C}$ display peak broadening which scales with the phason momentum of the diffraction peak, $G_{1}{ }^{11}$ High-resolution electron microscopy of slow cooled $\mathrm{Al}_{65} \mathrm{Cu}_{20} \mathrm{Fe}_{15}$ reveals a multiply twinned rhombohedral structure present at temperatures below approximately $700^{\circ} \mathrm{C} .^{12}$

For $\mathrm{Al}-\mathrm{Cu}-\mathrm{Ru}$, very little is known of the phase diagram. No ternary intermetallic compounds have been reported. ${ }^{13}$ Some assumptions concerning the phase diagram can be made simply because of the many similarities (size, electronegativity, etc.) between $\mathrm{Ru}$ and $\mathrm{Fe}$. Greater knowledge of this system would provide more clues regarding the stability of FCI alloys and their relationships with crystalline phases. To this end we have used rapid-solidification techniques to prepare alloys in the Al-Cu-Ru system and studied the resultant phases and their response to thermal treatments.

\section{EXPERIMENTAL PROCEDURE}

$\mathrm{Al}-\mathrm{Cu}-\mathrm{Ru}$ alloys were made by arc melting, in appropriate proportions, high-purity ( $>99.9 \%$ ) elemental constituents. To ensure complete mixing, each ingot was turned and remelted several times. Weight loss on alloying was typically less than $0.3 \%$. Ribbons were then produced from these ingots by melt spinning under argon at atmospheric pressure. The wheel material was copper and the tangential velocity was $30 \mathrm{~m} / \mathrm{s}$. Quartz crucibles 
were used with an orifice of $0.8 \mathrm{~mm}$.

A majority of the ribbon was then ground into powder for x-ray diffraction, differential thermal analysis (DTA) and heat treatment; some flakes were saved for transmission electron microscopy. X-ray diffraction was done on a Philips PW 1820 powder diffraction unit with $\mathrm{Cu} K \alpha$ radiation and a postsample monochromator. Differential thermal analysis on a Perkin-Elmer 1700 provided phase stability information. To anneal the material, the powder was wrapped in Ta foil and sealed in quartz capsules under high-purity Ar. Samples were quenched in water from the annealing temperature unless otherwise noted. Transmission electron microscopy was done on a Philips CM30 operating at $150 \mathrm{kV}$ and a JEOL 2000FX equipped with a Tracor-Northern energy dispersive spectroscopy system. Samples were thinned by ion milling at $3 \mathrm{kV}$.

\section{RESULTS}

\section{Compositional study}

Eleven compositions were examined in this study, as shown in Fig. 1. A fairly wide range of compositions was chosen in order to better determine phase relationships in this region of the ternary phase diagram.

After melt spinning, $x$-ray diffraction revealed that most samples consisted of a "disordered" icosahedral phase along with varying amounts of $\mathrm{Al}_{2} \mathrm{Cu}(\Theta)$ and $\mathrm{Al}$, depending on the starting composition. Diffraction patterns for several alloys are shown in Fig. 2. Table I lists the solidification products for each of the compositions studied. We use the term "disordered" here in a loose sense to include both chemical and topological defects. Close inspection of Fig. 2 reveals that the $x$-ray diffraction patterns seem more characteristic of the SI alloys than the FCI alloys. The clearest signal of the chem-

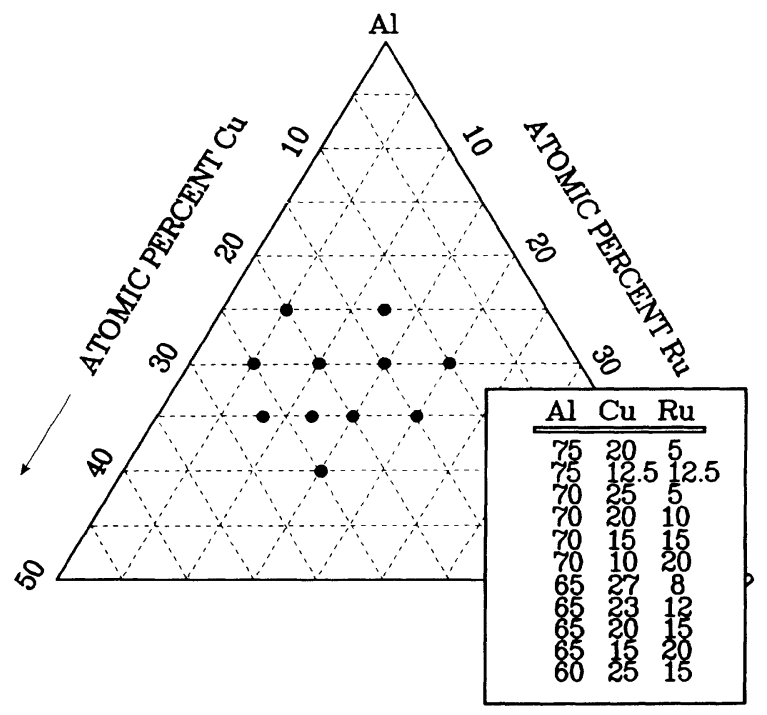

FIG. 1. Ternary phase diagram locating the compositions which were investigated in this study. Also shown is the list of compositions, in atomic percent.

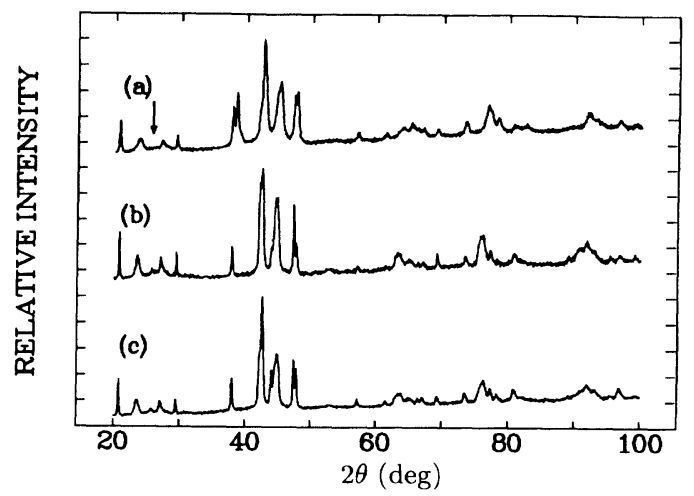

FIG. 2. X-ray diffraction patterns of rapidly solidified (a) $\mathrm{Al}_{75} \mathrm{Cu}_{20} \mathrm{Ru}_{5}$, (b) $\mathrm{Al}_{65} \mathrm{Cu}_{23} \mathrm{Ru}_{12}$, and (c) $\mathrm{Al}_{60} \mathrm{Cu}_{25} \mathrm{Ru}_{15}$. The arrow indicates the FCI signature peak. These display very little chemical ordering and possess a large amount of structural disorder, as seen by the large breadth of the peaks.

ical ordering which distinguishes the FCI alloys from SI alloys is a diffraction peak found at about $26^{\circ}$, marked by an arrow in Fig. 2. ${ }^{5}$ As seen in Fig. 2, this peak is of very low intensity. This is typical for all as-spun samples studied except $\mathrm{Al}_{70} \mathrm{Cu}_{15} \mathrm{Ru}_{15}$, which will be discussed separately below. The icosahedral peaks are also very broad, indicating that a large amount of structural disorder is also present in the as-spun material. The rather low degree of structural and chemical order in these as-spun Al-Cu-Ru alloys sharply contrasts with similar measurements for the Al-Cu-Fe system, which is very well ordered under identical solidification parameters. ${ }^{11}$

The as-spun microstructures for several alloys were examined by TEM. In all cases, the icosahedral phase formed as the primary dendrite. Depending on composition, either the $\Theta$ peritectic [Fig. 3(a)] or Al- $\Theta$ eutectic [Fig. 3(b)] forms interdendritically. The composition of the icosahedral phase in the $\mathrm{Al}_{65} \mathrm{Cu}_{23} \mathrm{Ru}_{12}$ sample, as determined by semiquantitative analysis of energy dispersive $x$-ray spectra, was found to be approximately $\mathrm{Al}_{53} \mathrm{Cu}_{30} \mathrm{Ru}_{17}$ at the dendrite tip and near $\mathrm{Al}_{65} \mathrm{Cu}_{23} \mathrm{Ru}_{12}$ toward the core. Also, some $\mathrm{Ru}$ was detected in the $\mathrm{Al}_{2} \mathrm{Cu}$ phase, while no $\mathrm{Si}$ (which may result from contamination from the quartz crucible during melt spinning) was detected in the as-spun material.

The internal microstructure of the icosahedral phase is also quite interesting in the as-spun material. The small length-scale variations in contrast, seen most clearly in Fig. 3(a), may be due to the presence of antiphase boundaries, ${ }^{14}$ since we have seen from the $x$-ray diffraction results that the degree of chemical ordering is small. We point out here that the microstructure of $\mathrm{Al}_{70} \mathrm{Cu}_{15} \mathrm{Ru}_{15}$ [Fig. 3(c)], which is well-ordered chemically [see, for example, Fig. 15 (a)], does not contain the same shortlength scale variations in contrast that is present in the other, more chemically disordered alloys. This supports the idea that the contrast is due to the presence of antiphase domains.

The microstructures obtained in this system are strikingly different from those obtained for rapidly solidified Al-Cu-Fe icosahedral alloys, which contain micrometer- 
TABLE I. Solidification and crystallization products for the Al-Cu-Ru alloys studied ( $I=$ icosahedral, $\Theta=\mathrm{Al}_{2} \mathrm{Cu}$, Tet $=$ tetragonal).

\begin{tabular}{|c|c|c|c|}
\hline \multirow{2}{*}{$\begin{array}{l}\text { Composition } \\
\text { (Al-Cu-Ru) }\end{array}$} & \multirow{2}{*}{$\begin{array}{c}\text { As-spun } \\
\text { phases }\end{array}$} & \multicolumn{2}{|c|}{ Crystallization } \\
\hline & & Temp. ${ }^{\circ} \mathrm{C}$ & Phases \\
\hline \multirow[t]{3}{*}{$75-20-5$} & $I, \boldsymbol{\Theta}, \mathrm{Al}$ & $446^{\circ}$ & $\Theta$ \\
\hline & & & Tet \\
\hline & & & $\mathrm{Al}$ \\
\hline \multirow[t]{3}{*}{$75-12.5-12.5$} & $I, \Theta, \mathrm{Al}$ & 435 & $\theta$ \\
\hline & & & Tet \\
\hline & & & Al \\
\hline \multirow[t]{3}{*}{$70-25-5$} & $I, \Theta$ & 400 & $\Theta$ \\
\hline & & & Tet \\
\hline & & & Al \\
\hline \multirow[t]{2}{*}{$70-20-10$} & $I, \Theta$ & 450 & $\Theta$ \\
\hline & & & Tet \\
\hline $70-15-15$ & $I, \Theta$ & 530 & Tet \\
\hline \multirow[t]{3}{*}{$70-10-20$} & $I, \Theta$ & 510 & Tet \\
\hline & & & $\mathrm{Al}_{2} \mathrm{Ru}$ \\
\hline & & & $?^{\mathrm{a}}$ \\
\hline \multirow[t]{2}{*}{$65-27-8$} & $I, \Theta$ & 400 & $\Theta$ \\
\hline & & & Tet \\
\hline $65-23-12$ & $I, \Theta$ & 495 & Tet \\
\hline $65-20-15$ & $I, \Theta$ & 485 & Tet \\
\hline \multirow[t]{2}{*}{$65-15-20$} & $I, \Theta, ?$ & 540 & Tet \\
\hline & & & $\begin{array}{l}\mathrm{Al}_{2} \mathrm{Ru} \\
?^{\mathrm{a}}\end{array}$ \\
\hline \multirow[t]{2}{*}{$60-25-15$} & $I, \Theta$ & 514 & $\theta$ \\
\hline & & & Tet \\
\hline
\end{tabular}

${ }^{a}$ These phases, of different structures, could not be indexed to any known Al-Ru phases.

sized equiaxed grains. With the clear difference in the solidification microstructures, it is apparent that the two ternary phase diagrams, especially the liquidus surfaces and the underlying metastable diagrams, are quite different for the Al-Cu-Ru and Al-Cu-Fe systems.

The solidification microstructure reveals important details concerning the Al-Cu-Ru alloy system. First of all, it is apparent that during solidification the planar solidliquid interface develops an instability, resulting in celldendrite formation and diffusion-controlled growth of the icosahedral phase into the liquid. In short, the solidification proceeds classically, as would be observed in periodic crystalline alloy systems. Secondly, by identifying primary phases and the compositions over which they form, the metastable diagram can be determined. In this case, the icosahedral phase forms over a very large compositional region, indicating that the metastable extension of the icosahedral solidus is the solidification path followed during rapid solidification.

\section{Thermal stability}

The thermal stability of the as-spun material was investigated by DTA. For each composition studied, an exothermic peak exists as the first response to heating (Fig. 4). Since this is rapidly solidified material, it is safe to assume that exothermic reactions indicate that the as-spun icosahedral phase is metastable. The endothermic reactions seen in Fig. 4 at 550 and $590^{\circ} \mathrm{C}$ correspond to eutectic and $\mathrm{Al}_{2} \mathrm{Cu}$ melting, respectively. The products of the crystallization for each alloy were determined by annealing for $30 \mathrm{~min}$ at temperatures just beyond the exothermic peak. The crystallization temperatures and products are shown in Table I. We find that the primary crystallization product is a tetragonal phase $(a=6.45 \AA$, $c=14.89 \AA$ ), which has been determined from electron and $\mathrm{x}$-ray diffraction to be isostructural with $\mathrm{Al}_{7} \mathrm{Cu}_{2} \mathrm{Fe} .{ }^{15}$ Interestingly, this structure does not contain icosahedral clusters or other atomic configurations which would make it an approximant phase. Two of the phases present after crystallization (marked with question marks) did not index to currently known phases, and complete indexing was not possible because of the limited number of lines present in the diffractometer traces. From the crystallization data, we can draw an isothermal section of the ternary diagram for this region at temperatures below $\sim 500^{\circ} \mathrm{C}$ (Fig. 5).

\section{Annealing study}

To determine high-temperature phase stabilities, samples were annealed at $800^{\circ} \mathrm{C}$ for various amounts of time, generally ranging from $24 \mathrm{~h}$ to one week. Of the compositions studied, the FCI phase field at $800^{\circ} \mathrm{C}$ was found to encompass $\mathrm{Al}_{65} \mathrm{Cu}_{23} \mathrm{Ru}_{12}, \mathrm{Al}_{65} \mathrm{Cu}_{20} \mathrm{Ru}_{15}, \mathrm{Al}_{70} \mathrm{Cu}_{20} \mathrm{Ru}_{10}$, and $\mathrm{Al}_{70} \mathrm{Cu}_{15} \mathrm{Ru}_{15}$. X-ray diffraction revealed essentially single phase FCI alloys for these compositions (Fig. 6). Nearby compositions contained the FCI phase mixed with either a crystalline phase or liquid. The FCI structures are very well-ordered chemically, shown by the intensity of the peak near $26^{\circ}$ two theta, and have a high 
degree of structural integrity, illustrated by the narrow linewidths.

Since we have seen from the previous section that the tetragonal phase is the major phase present at lower temperatures, and we obtain the FCI phase at higher temperatures, the transformation to the FCI phase on heating should be marked by a peak in the DTA scan of the tetragonal phase. In fact, strong endothermic peaks at temperatures from $\approx 670$ to $710^{\circ} \mathrm{C}$, depending on composition, do exist for all of these alloys and mark the tetragonal to FCI transformation (Fig. 7). The presence of endothermic events indicates that the phase transformation is from a low-temperature stable phase of the system

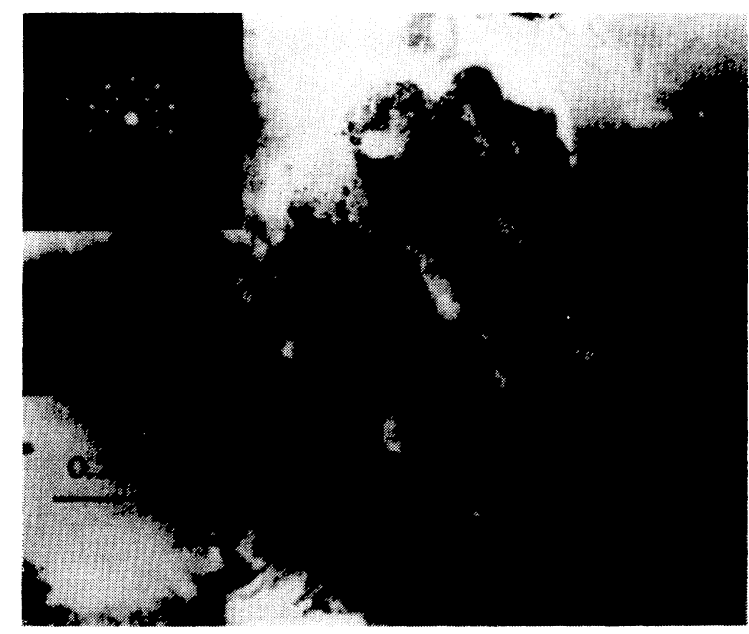

(a)

(tetragonal) to the high-temperature FCI phase.

In order to verify that these endothermic events correspond to the tetragonal to FCI transformation, annealing experiments, in which the alloys were heat treated at temperatures just below and above the observed endotherms, were completed. These results confirm that these DTA peaks correspond to the tetragonal to FCI transformation, as the tetragonal phase was obtained upon heat treatment below the endotherm and the FCI phase upon heat treatment above the endotherm. A DTA scan of a sample first annealed at $800^{\circ} \mathrm{C}$ to obtain the FCI phase shows no response to heating in this temperature range (Fig. 7), further confirming that the endotherms corre-
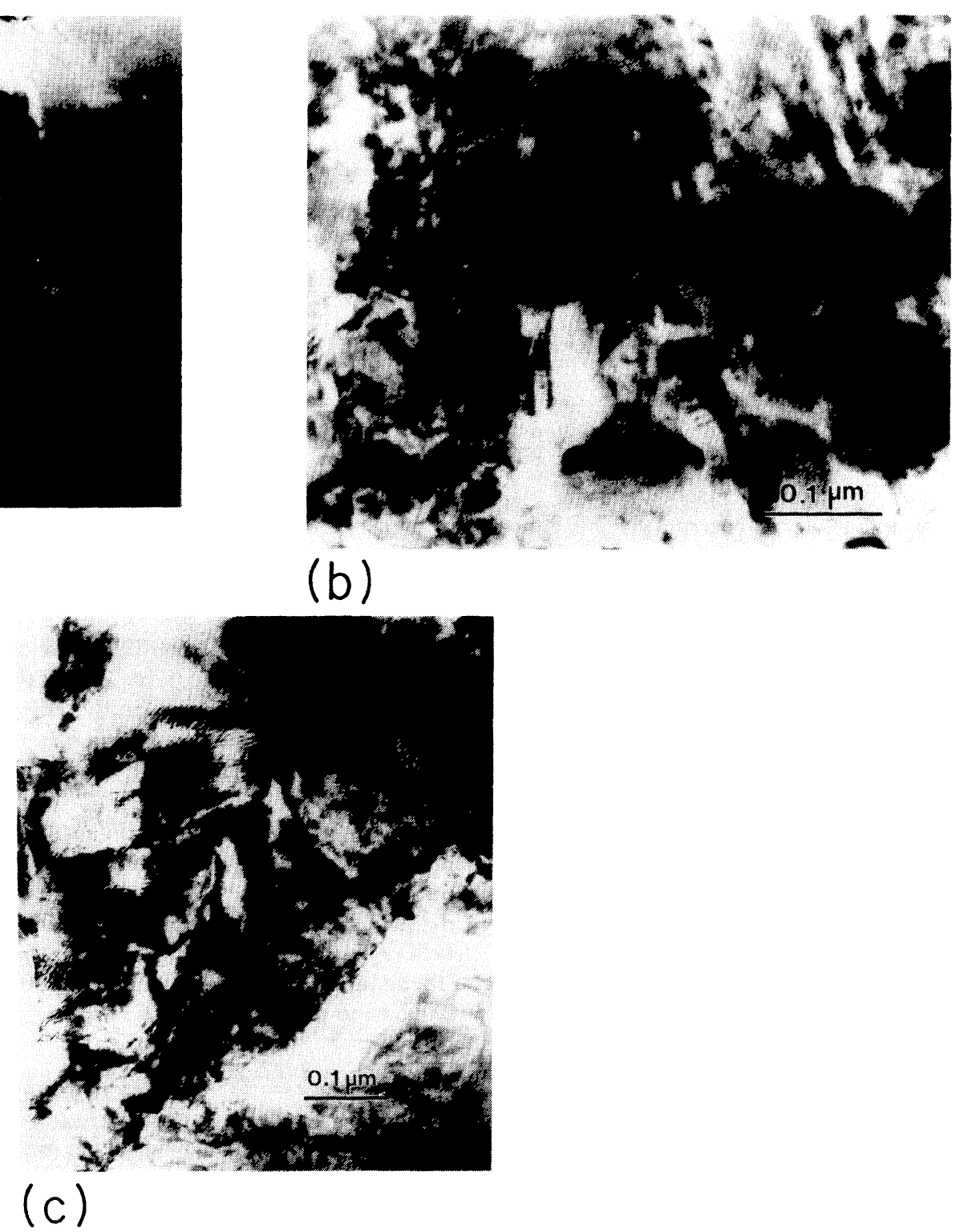

FIG. 3. Transmission electron micrographs of (a) $\mathrm{Al}_{65} \mathrm{Cu}_{23} \mathrm{Ru}_{12}$, which shows the dendritic icosahedral phase surrounded by the $\mathrm{Al}_{2} \mathrm{Cu}$ that forms peritectically (the five-fold diffraction pattern is shown in the inset); (b) $\mathrm{Al}_{75} \mathrm{Cu}_{20} \mathrm{Ru}_{5}$, with primary solidification of the icosahedral phase (left) and eutectic formation interdendritically (seen best in the upper right); and (c) $\mathrm{Al}_{70} \mathrm{Cu}_{15} \mathrm{Ru}_{15}$, which shows a more equiaxed morphology and does not contain the same contrast observed in the other samples (see text for more details). 


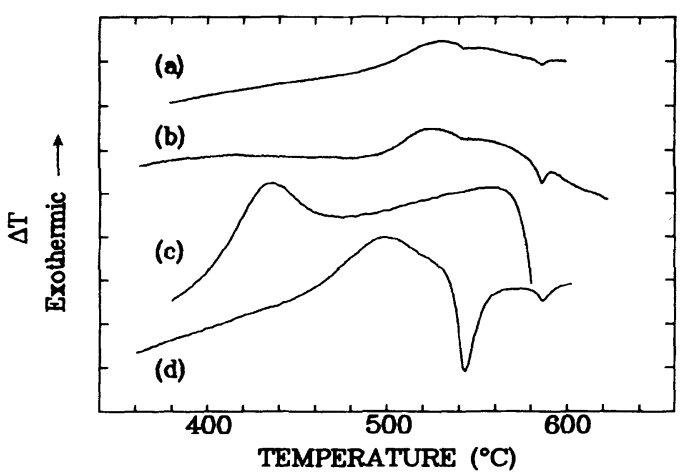

FIG. 4. Differential thermal analysis of the as-spun material at all compositions reveal exothermic reactions. The scans shown are for (a) $\mathrm{Al}_{65} \mathrm{Cu}_{20} \mathrm{Ru}_{15}$, (b) $\mathrm{Al}_{65} \mathrm{Cu}_{23} \mathrm{Ru}_{12}$, (c) $\mathrm{Al}_{65} \mathrm{Cu}_{27} \mathrm{Ru}_{8}$, and (d) $\mathrm{Al}_{70} \mathrm{Cu}_{20} \mathrm{Ru}_{10}$. Values of the crystallization temperatures for all compositions are shown in Table I $\left(10^{\circ} \mathrm{C} / \mathrm{min}\right.$ heating rate).

spond to the tetragonal to FCI transformation.

For three of the four compositions studied in the FCI phase field, only a single endotherm, marking the tetragonal to FCI transformation, was observed above $600^{\circ} \mathrm{C}$. In the case of $\mathrm{Al}_{65} \mathrm{Cu}_{23} \mathrm{Ru}_{12}$, a small amount of eutectic and $\mathrm{Al}_{2} \mathrm{Cu}$ coexist with the tetragonal phase, as indicated by their respective melting events in Fig. $7(\mathrm{a})$. We note that DTA is much more sensitive than $x$-ray diffraction to the presence of minute quantities of additional phases, as the $\mathrm{x}$-ray diffraction scan of this material showed only the tetragonal phase present. It is unclear what the other endothermic peak [at approximately $640^{\circ} \mathrm{C}$ in Fig. 7(a)] is due to since only the tetragonal phase results when the material is annealed at temperatures below $670^{\circ} \mathrm{C}$, as determined by $x$-ray diffraction.

Since the FCI phase results from an endothermic reaction, slow cooling of the material from higher temperatures might be expected to form the tetragonal phase,

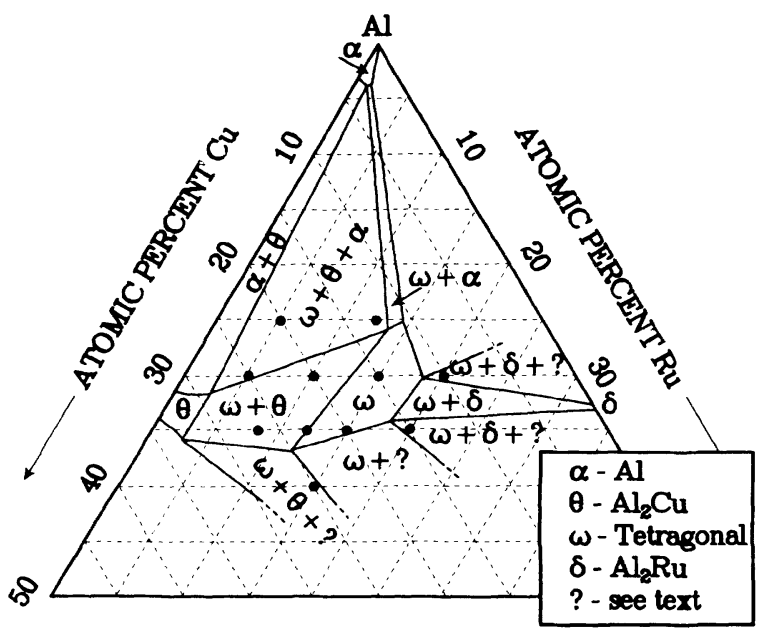

FIG. 5. Approximate isothermal section of the Al-Cu-Ru ternary phase diagram at $\approx 500^{\circ} \mathrm{C}$ in the region investigated. Solid circles are compositions investigated.

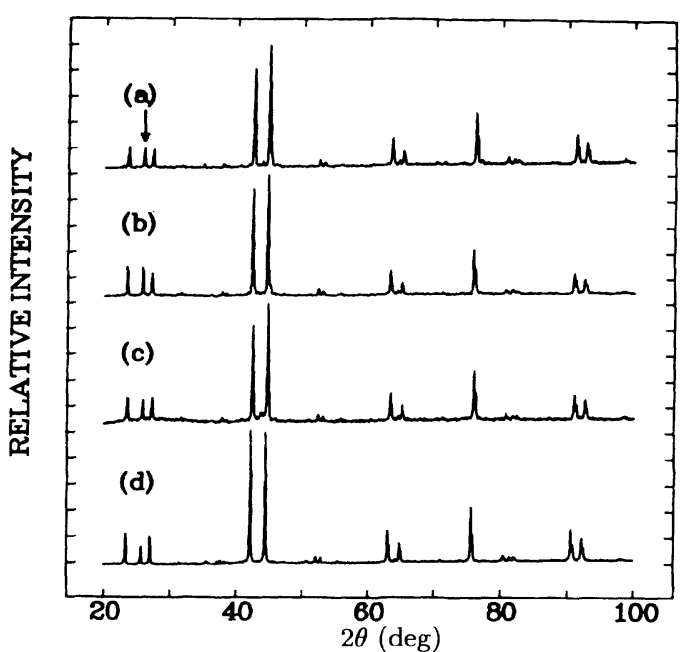

FIG. 6. X-ray diffraction scans of (a) $\mathrm{Al}_{65} \mathrm{Cu}_{23} \mathrm{Ru}_{12}$, (b) $\mathrm{Al}_{70} \mathrm{Cu}_{20} \mathrm{Ru}_{10}$, (c) $\mathrm{Al}_{65} \mathrm{Cu}_{20} \mathrm{Ru}_{15}$ and (d) $\mathrm{Al}_{70} \mathrm{Cu}_{15} \mathrm{Ru}_{15}$ annealed at $800^{\circ} \mathrm{C}$ for $48 \mathrm{~h}$, which produces the FCI phase. The FCI signature peak is arrowed.

which is the low temperature equilibrium phase. However, slow cooling of $\mathrm{Al}_{65} \mathrm{Cu}_{23} \mathrm{Ru}_{12}$ at $16^{\circ} \mathrm{C} / \mathrm{h}$ after annealing at $800^{\circ} \mathrm{C}$ produces only the FCI phase (Fig. 8). No transformation to the tetragonal phase occurred. We believe that this indicates that the process of the FCI to tetragonal transformation is limited, either by difficulties in nucleating the tetragonal phase, or by the growth kinetics. Extended heat treatment at temperatures below the transition also failed to produce the tetragonal phase. For example, samples of $\mathrm{Al}_{65} \mathrm{Cu}_{23} \mathrm{Ru}_{12}$ first annealed at $800^{\circ} \mathrm{C}$ to obtain the FCI phase, were then held at $500^{\circ} \mathrm{C}$ for up to ten days without the formation of the tetragonal phase. Similar results were found for the other compositions.

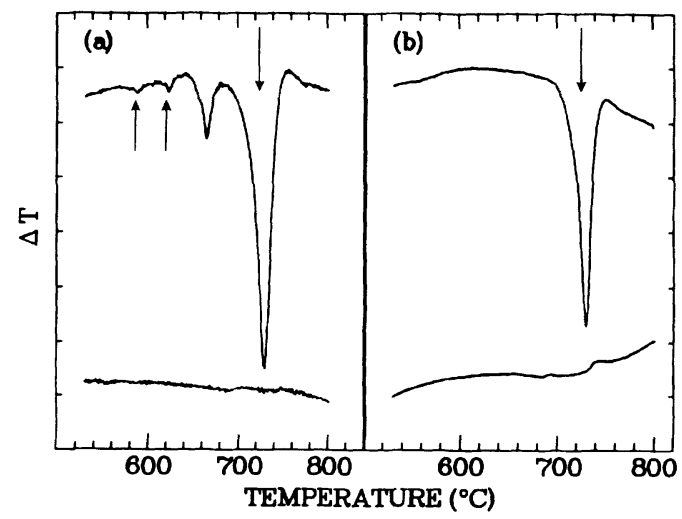

FIG. 7. Differential thermal analysis of (a) $\mathrm{Al}_{65} \mathrm{Cu}_{23} \mathrm{Ru}_{12}$ and (b) $\mathrm{Al}_{65} \mathrm{Cu}_{20} \mathrm{Ru}_{15}$. The top scans are of material annealed at $500{ }^{\circ} \mathrm{C}$ to obtain the tetragonal phase, while the bottom scans are of material in the FCI phase, obtained by annealing at $800^{\circ} \mathrm{C}$. The top scans show large endothermic reactions which are attributed to the tetragonal to FCI transformation (marked by arrows). The lack of these in the lower scans substantiates this. In (a), the smaller peaks at lower temperatures (marked by arrows) are from eutectic and $\mathrm{Al}_{2} \mathrm{Cu}$ melting, respectively. $\left(10^{\circ} \mathrm{C} / \mathrm{min}\right.$ heating rate. 


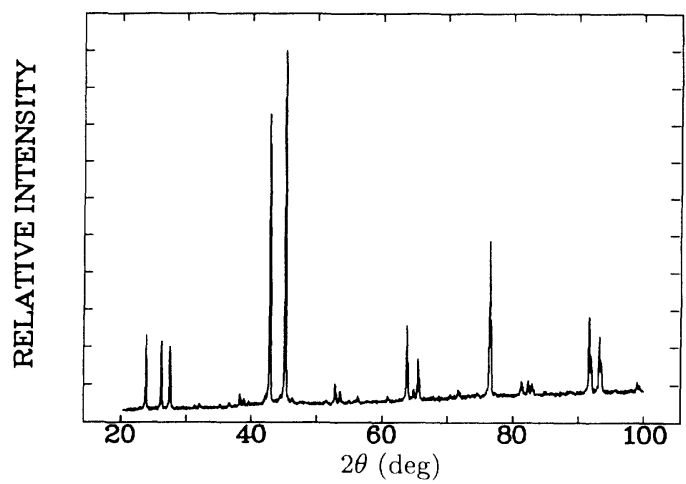

FIG. 8. X-ray diffraction scan of $\mathrm{Al}_{65} \mathrm{Cu}_{23} \mathrm{Ru}_{12}$ which was cooled at $16^{\circ} \mathrm{C} / \mathrm{h}$ from 800 to $450^{\circ} \mathrm{C}$. This illustrates the kinetic limitations of the FCI to tetragonal transformation upon cooling.

On the other hand, the presence of a second phase with the FCI phase apparently assists in the FCI to tetragonal transformation. For $\mathrm{Al}_{70} \mathrm{Cu}_{20} \mathrm{Ru}_{10}$, annealing at $800^{\circ} \mathrm{C}$ for just $24 \mathrm{~h}$ leaves a small amount of $\mathrm{Al}_{2} \mathrm{Cu}$ present. Now, we observe the transformation from the FCI to tetragonal phase upon further heat treatment at $500{ }^{\circ} \mathrm{C}$ (Fig. 9). Single-phase FCI material, which can be obtained by annealing at $800^{\circ} \mathrm{C}$ for $48 \mathrm{~h}$, does not contain $\mathrm{Al}_{2} \mathrm{Cu}$ and does not transform to the tetragonal phase on annealing below $700{ }^{\circ} \mathrm{C}$. Evidently, the $\mathrm{Al}_{2} \mathrm{Cu}$ second phase assists the transformation, most probably by providing a nucleation site for the tetragonal phase.

\section{Approximants}

It is interesting that we observe a tetragonal to FCI transformation, upon heating, in the Al-Cu- $\mathrm{Ru}$ system even though the local atomic arrangements in the tetragonal phase bear no apparent relationship to that found in typical icosahedral alloys. In order to more carefully investigate the transformation, samples annealed at $800^{\circ} \mathrm{C}$ as a function of time were investigated, with the resultant

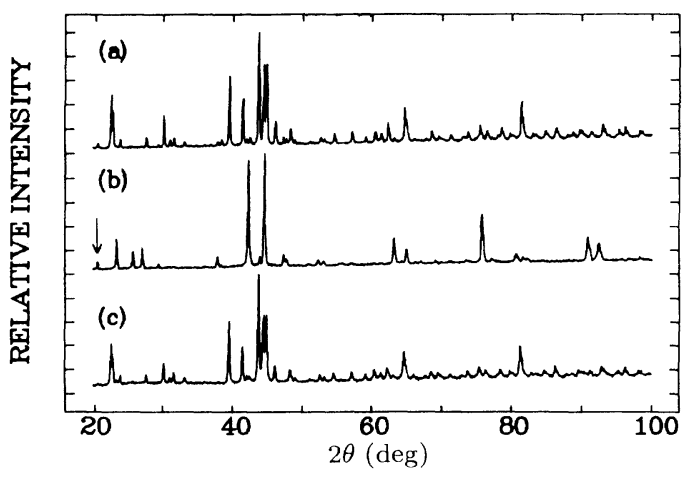

FIG. 9. X-ray diffraction scans of $\mathrm{Al}_{70} \mathrm{Cu}_{20} \mathrm{Ru}_{10}$ annealed (a) at $500^{\circ} \mathrm{C}$ for $24 \mathrm{~h}$, which contains the tetragonal and $\mathrm{Al}_{2} \mathrm{Cu}$ phases, and then (b) at $800^{\circ} \mathrm{C}$ for $24 \mathrm{~h}$, with an $\mathrm{Al}_{2} \mathrm{Cu}$ peak marked. In (c) with the presence of $\mathrm{Al}_{2} \mathrm{Cu}$ the transformation back to the tetragonal phase upon annealing at $500^{\circ} \mathrm{C}$ occurs. structures examined by TEM.

Selected-area diffraction (SAD) of as-spun ribbon annealed at $800^{\circ} \mathrm{C}$ for $48 \mathrm{~h}$ results in a relatively defect-free FCI structure, with little or no phason disorder [Fig. 10(a)]. However, deviations characteristics of phason disorder, such as irregularly shaped pentagons and an asymmetric first ring of diffraction spots, do exist in the fivefold SAD pattern of material annealed for shorter times at $800^{\circ} \mathrm{C}$ [Figs. 10(b) and $10(\mathrm{c})$ ]. Lattice imaging of the latter material revealed that the structure in fact contains small regions of periodicity (Fig. 11). The many small areas of crystallinity surrounded by heavily phasonstrained quasicrystalline regions indicate that the material is in the midst of transforming to the FCI phase. The phason disorder is evidenced by the jogs and discontinuities in the lattice image (Fig. 11). ${ }^{16}$

The structure of the crystalline phase has been determined to be rhombohedral, with $a \approx 26 \AA$ and $\alpha=36^{\circ}$, from lattice imaging of the twofold, threefold, and fivefold axes. Convergent-beam electron-diffraction (CBED) patterns show that the structure contains fivefold symmetry (Fig. 12). CBED patterns do not necessarily reveal the symmetry of the crystal lattice, but can instead reveal symmetry of atomic configurations within the unit cell when examining large unit cell structures. ${ }^{4}$ In this structure the major scattering centers have fivefold symmetry, indicating that the structure contains local icosahedral symmetry. The similarity of the SAD patterns shown in Fig. 10 suggests that the long-range positional order may be similar in the two structures.

It was possible, by varying the annealing time, to observe this transition in all four of the FCI compositions, indicating a transformation sequence of

as-spun $\rightarrow$ tetragonal $\rightarrow$ approximant $\rightarrow$ FCI

upon heating the as-spun material to $800^{\circ} \mathrm{C}$. To verify that this approximant structure was indeed between the tetragonal and FCI phases, $\mathrm{Al}_{65} \mathrm{Cu}_{20} \mathrm{Ru}_{15}$ ribbon was annealed at $600{ }^{\circ} \mathrm{C}$ to obtain the tetragonal phase and then $800^{\circ} \mathrm{C}$ for $10 \mathrm{~min}$. This material also displayed the structural characteristics discussed above.

This crystalline rhombohedral approximant may either be a stable structure in the Al-Cu-Ru system, albeit over a very small temperature region since it has not been isolated as of yet, or that it is an intermediate structure necessary for the transformation to the FCI phase from the tetragonal phase. Either of these would seem to indicate that the approximant phase is necessary to form the FCI phase, since the tetragonal phase is apparently not an approximant phase. Also, the presence of phason disorder suggests that the transformation may be phason driven. ${ }^{11}$

Another approximant phase was also observed in the $\mathrm{Al}-\mathrm{Cu}-\mathrm{Ru}$ system at a composition near, but not in, the FCI single-phase field. Annealing $\mathrm{Al}_{60} \mathrm{Cu}_{25} \mathrm{Ru}_{15}$ at $800^{\circ} \mathrm{C}$ for $24 \mathrm{~h}$ results in the $\mathrm{Al}_{2} \mathrm{Cu}, \mathrm{AlRu}$, and FCI phases after quenching [Fig. 13(a)]. However, further annealing at $800^{\circ} \mathrm{C}$ results in a structure apparently similar to the FCI phase, with clusters of peaks at similar diffracting angles [Fig. 13(b)]. Electron diffraction results of this phase re- 
veal that it is indeed crystalline, with intensity modulations similar to that observed in the FCI phase (Fig. 14), indicating that clusters of atoms within the unit cell have icosahedral symmetry. Angles between the twofold, threefold, and fivefold orientations agreed with the icosahedral point group symmetry. The crystalline phase indexes to a simple cubic structure with $a=12.4 \AA$. A more complete description of this structure will be presented elsewhere. ${ }^{15}$ Annealing this approximant structure at higher temperatures $\left(900^{\circ} \mathrm{C}\right)$ for $24 \mathrm{~h}$ results in a multiphase structure, which includes the FCI, AlRu, $\mathrm{Al}_{2} \mathrm{Cu}$, and an unidentified phase. The exact composition of the approximant phase has not been determined at this time. Further studies may provide interesting informa-

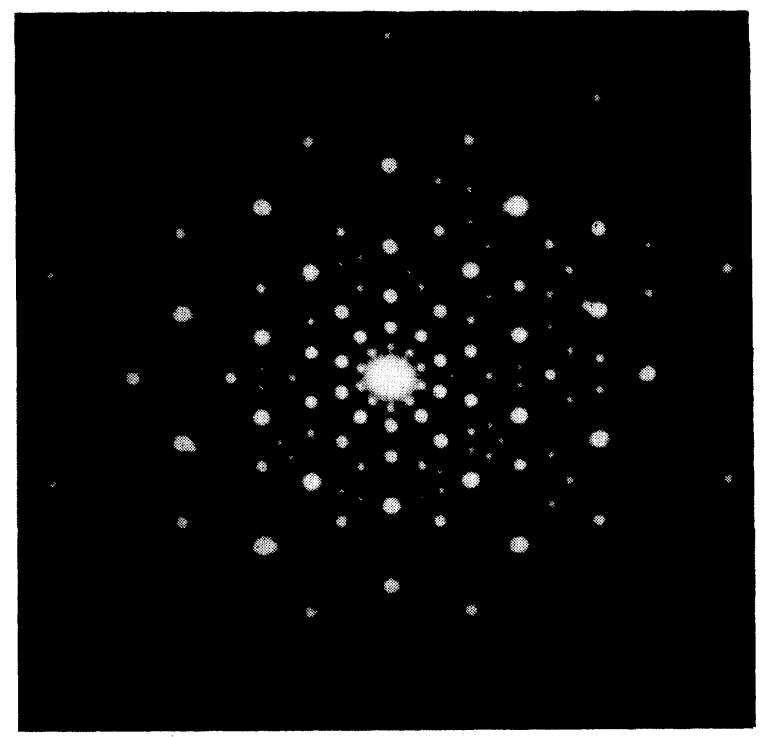

(a) tion on the direct transformation between quasicrystalline and crystalline phases.

$$
\mathrm{Al}_{70} \mathrm{Cu}_{15} \mathbf{R u}_{15}
$$

As was mentioned above, as-spun $\mathrm{Al}_{70} \mathrm{Cu}_{15} \mathrm{Ru}_{15}$ is better ordered, both chemically and topologically, than the other alloys studied, as indicated by the intensity of the $x$-ray diffraction peak at about $26^{\circ}$ two theta and the relatively narrower diffraction peaks in the pattern [Fig. 15(a)]. Indeed, this FCI signature peak is nearly as intense in the as-solidified material as it is in the material heat treated at $800^{\circ} \mathrm{C}$ [see Fig. 6(d)]. The concomitant increase in the degree of chemical ordering and the de-

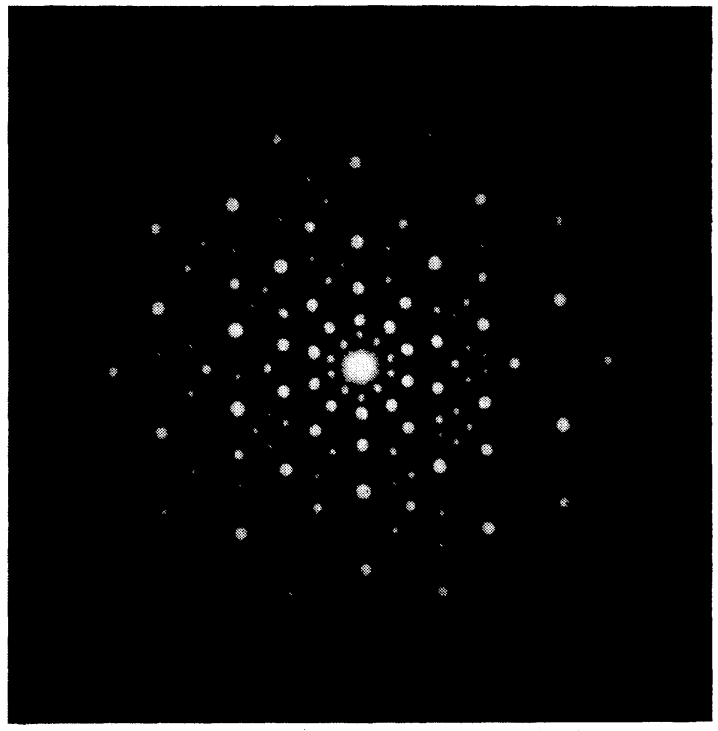

(b)

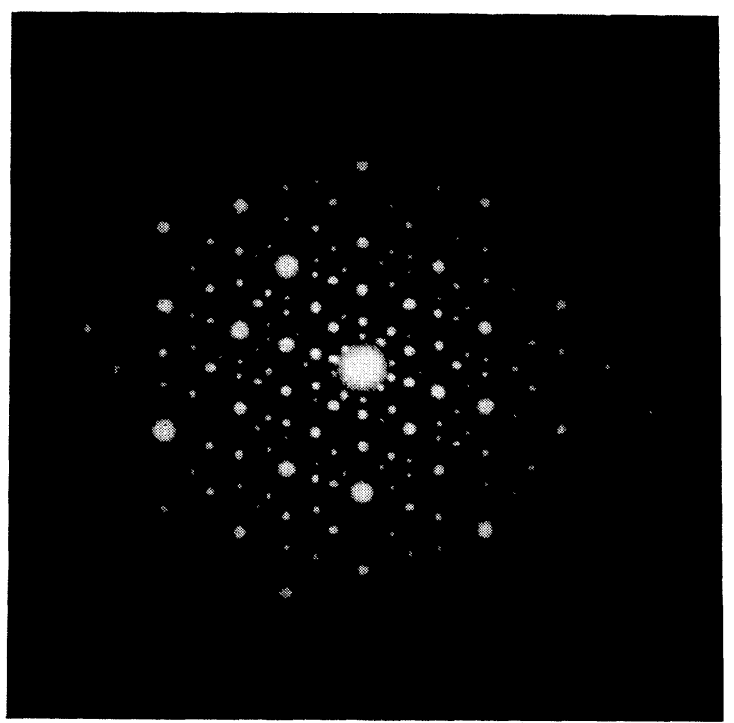

(c)

FIG. 10. SAD patterns of $\mathrm{Al}_{70} \mathrm{Cu}_{20} \mathrm{Ru}_{10}$ annealed at $800^{\circ} \mathrm{C}$ for (a) $48 \mathrm{~h}$ and (b) $7.5 \mathrm{~h}$. (c) $\mathrm{Al}_{65} \mathrm{Cu}_{30} \mathrm{Ru}_{15}$ annealed at $800{ }^{\circ} \mathrm{C}$ for $1 \mathrm{~h}$. 


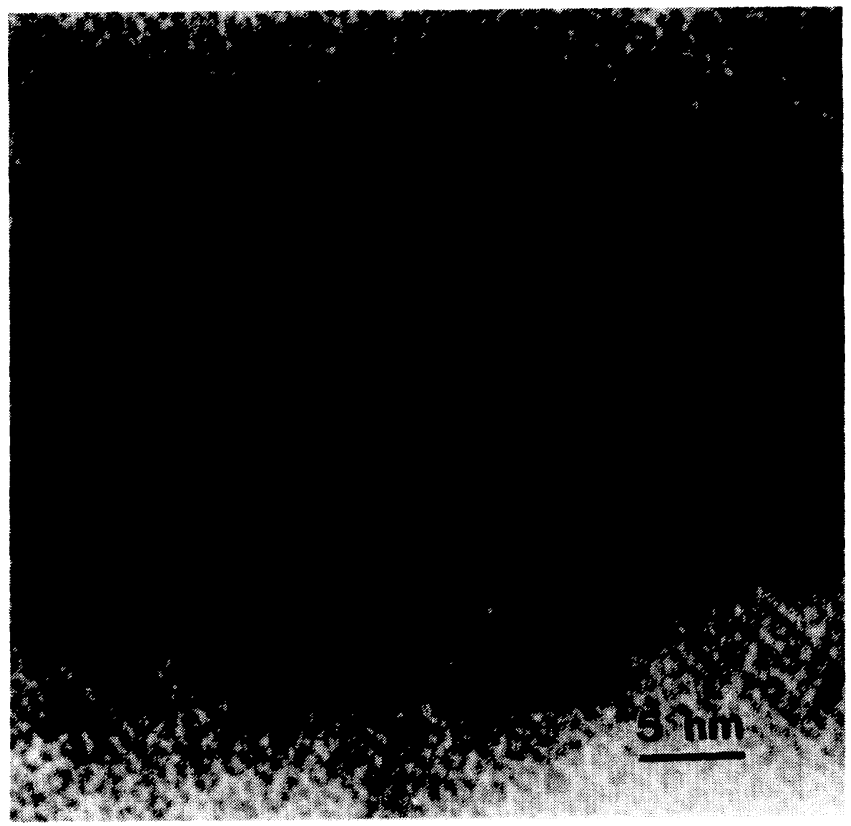

FIG. 11. High-resolution electron micrograph of $\mathrm{Al}_{70} \mathrm{Cu}_{20} \mathrm{Ru}_{10}$ along the direction shown in Fig. 10(b). Small regions of periodicity are highlighted.

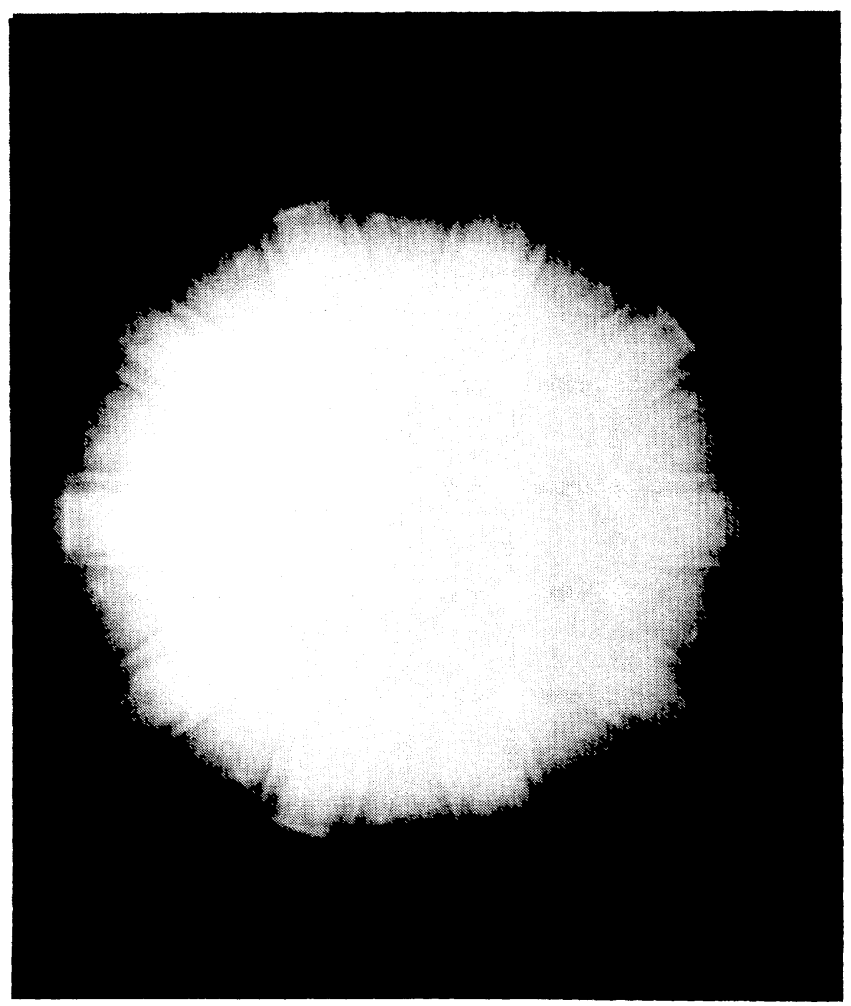

FIG. 12. Convergent beam electron diffraction (CBED) pattern of the fivefold axis shown in Figs. 10(b) and 11. The higher-order Laue zones (HOLZ) display fivefold symmetry.

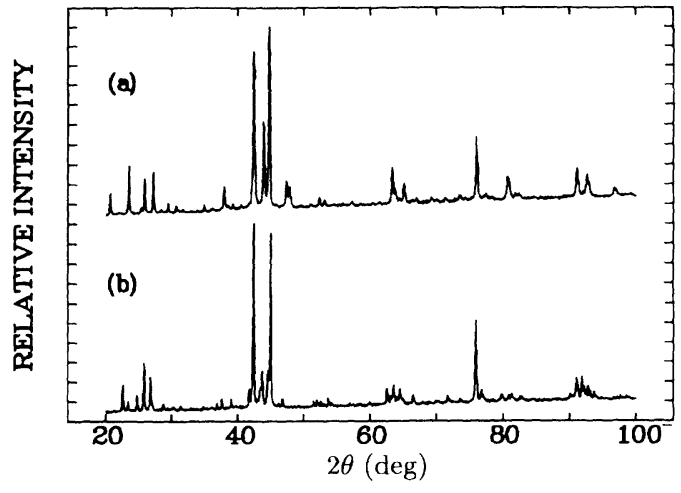

FIG. 13. X-ray diffraction scans of $\mathrm{Al}_{60} \mathrm{Cu}_{25} \mathrm{Ru}_{15}$ annealed at $800^{\circ} \mathrm{C}$ for (a) $24 \mathrm{~h}$ and (b) $96 \mathrm{~h}$.

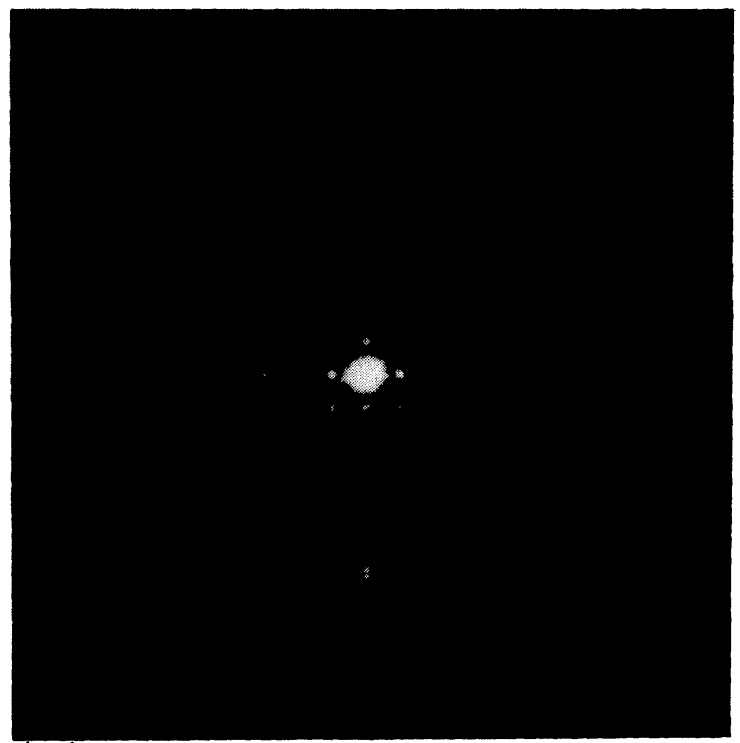

(a)

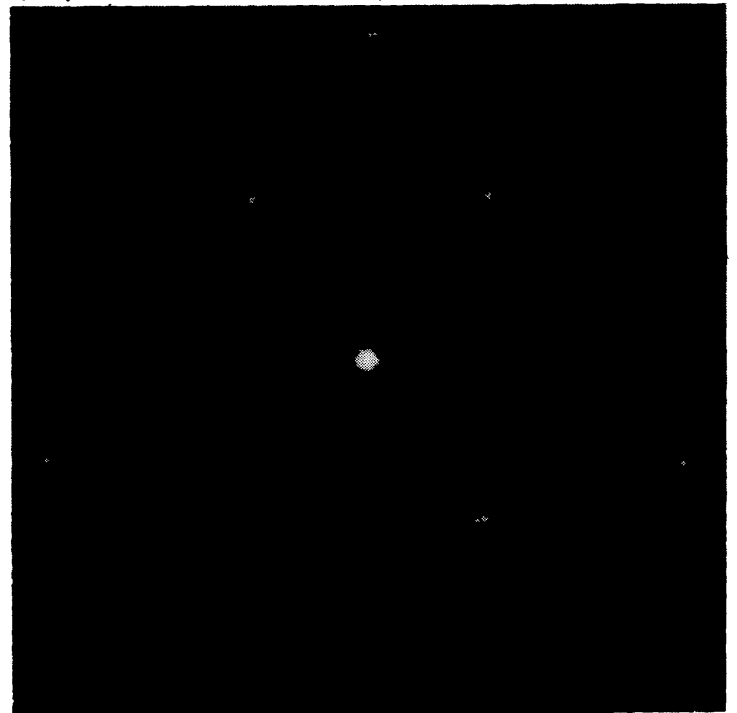

(b)

FIG. 14. SAD patterns of the cubic approximant phase along icosahedral (a) twofold and (b) fivefold directions. The directions within the cubic unit cell correspond to (a) $\langle 100\rangle$ and (b) irrational zone axes. 


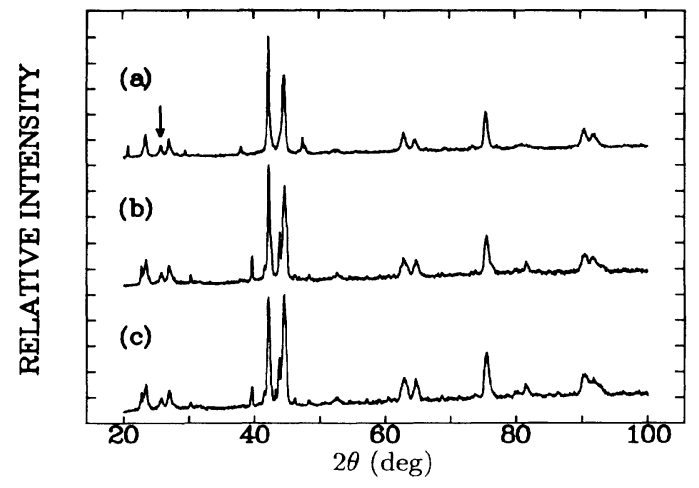

FIG. 15. X-ray diffraction scans of $\mathrm{Al}_{70} \mathrm{Cu}_{15} \mathrm{Ru}_{15}$ (a) as-spun, (b) after annealing $30 \mathrm{~min}$ at $600^{\circ} \mathrm{C}$, and (c) after annealing $24 \mathrm{~h}$ at $600^{\circ} \mathrm{C}$. The superlattice peak (arrowed) in (a) is much more intense than that seen for other alloys (see Fig. 3). Annealing produces only partial crystallization to the tetragonal phase.

crease in peak widths supports the notion of a close relationship between chemical and topological order in icosahedral alloys. ${ }^{17}$

Although an exothermic peak is observed by DTA at $530^{\circ} \mathrm{C}$, annealing at $600^{\circ} \mathrm{C}$ results in only partial transformation to the tetragonal phase [Figs. 15(b) and 15(c)]. We speculate that in this alloy crystallization may be inhibited by the smaller degree of compositional variation, or even perhaps topological disorder, within the icosahedral phase, reducing the diffusional driving force (i.e., chemical potential difference) for the reaction to go to completion. We point out that the lack of a complete transformation to the tetragonal phase does not indicate that the FCI phase is a stable phase at lower temperatures, since an exothermic reaction still occurs upon heating the as-spun material and in no other composition nearby is there a two- or three-phase region containing the FCI phase.

\section{CONCLUSIONS}

In this study of melt-spun Al-Cu-Ru alloys we have found that the icosahedral phase, generally disordered both chemically and topologically, is the primary solidification product of all the alloys investigated. It is interesting to compare this to the Al-Cu-Fe system, which upon melt spinning forms a chemically and topologically well-ordered icosahedral phase over a very limited compositional region, with the composition of the FCI phase limited by the equilibrium phase diagram. Conversely, in the Al-Cu-Ru system the icosahedral phase forms metastably with large variations in composition within the icosahedral phase. The differences in the solidification products of the two systems most probably stems from the differing thermodynamics, with the various factors, most notably the $T_{0}$ lines, promoting the formation of metastable phases in the Al-Cu-Ru system and not in the Al-Cu-Fe system.

The metastable phase formed upon rapid solidification transforms to equilibrium crystalline phases, primarily the tetragonal phase, upon heating. We then observe an endothermic transformation to a well-ordered FCI phase, indicating that both the tetragonal and FCI phases are equilibrium phases of the system. It is quite interesting that in this case the tetragonal phase apparently is not an approximant phase. However, the necessity of an approximant phase for the formation of the FCI phase was evidenced by an intermediate rhombohedral structure which exists between the tetragonal and FCI phases. Furthermore, significant phason strain is introduced during this transition. In the SI alloys, phason strain is frozen into quasicrystalline structures upon solidification. ${ }^{18}$ Phason strain has also been considered as a path for transforming quasicrystalline structure to crystalline structures. ${ }^{19}$ Here, we find that the formation of the FCI phase from a crystalline phase involves a heavily phason-strained intermediate quasicrystalline structure.

Although not thermodynamically stable, the FCI phase is kinetically stable at temperatures below $\approx 650^{\circ} \mathrm{C}$ in the absence of other phases. Others consider the chemical order to be a major contribution to the energetic stabilization of the FCI phase. ${ }^{19}$ In the as-spun Al$\mathrm{Cu}-\mathrm{Ru}$ alloys, it appears that chemical, or perhaps topological, disorder provides a means of overcoming the activation barrier for the formation of the equilibrium tetragonal phase. However, it is difficult to distinguish between the structural and chemical ordering contributions to the kinetic stability of the FCI phase since both types of disorder are present to a large degree in the asspun material.

\section{ACKNOWLEDGMENTS}

The authors would like to thank K. W. Dennis, L. S. Chumbley, L. X. He, and M. J. Kramer for insightful discussions. Ames Laboratory is operated by Iowa State University for the USDOE under Contract No. W-7405ENG-82. K. F. K. acknowledges partial support by the National Science Foundation under Grant No. DMR8903081 .
*Also with the Department of Materials Science and Engineering, Iowa State University, Ames, IA 50011.

${ }^{\dagger}$ Also with the Department of Physics, Iowa State University, Ames, IA 50011.

${ }^{1}$ D. Shectman, I. Blech, D. Gratias, and J. W. Cahn, Phys. Rev. Lett. 53, 1951 (1984).

${ }^{2}$ M. Audier and P. Guyot, Philos. Mag. B 53, L43 (1986); V. Elser and C. Henley, Phys. Rev. Lett. 55, 2883 (1985).

${ }^{3}$ M. A. Marcus and V. Elser, Philos. Mag. B 54, L101 (1986).
${ }^{4}$ L. E. Levine, J. C. Holzer, P. C. Gibbons, and K. F. Kelton (unpublished).

${ }^{5}$ C. A. Guryan, A. I. Goldman, P. W. Stephens, K. Hiraga, A. P. Tsai, A. Inoue, and T. Masumoto, Phys. Rev. Lett. 62, 2409 (1989); P. Bancel, ibid. 63, 2741 (1989); 64, 496 (1990).

${ }^{6}$ P. M. Horn, W. Malzfeldt, D. P. Divincenzo, J. Toner, and R. Gambino, Phys. Rev. Lett. 55, 2324 (1986).

${ }^{7}$ G. Onoda, P. Steinhardt, D. Divincenzo, and J. Socolar, Phys. Rev. Lett. 60, 2653 (1988); 62, 1210 (1989). 
${ }^{8}$ See, for example, V. Elser, Phys. Rev. Lett. 54, 1730 (1985); M. Widom, K. Strandburg, and R. H. Swendsen, ibid. 58, 706 (1987); M. Widom, in Proceedings of the 25th Anniversary Adriatico Research Conference on Quasicrystals, edited by M. Jaric and S. Lundqvist (World Scientific, Singapore, 1990), p. 337.

${ }^{9}$ A. J. Bradley and H. J. Goldschmidt, J. Inst. Met. 65, 403 (1939).

${ }^{10}$ F. W. Gayle, A. J. Shapiro, F. S. Biancaniello, and W. J. Boettinger (unpublished).

${ }^{11}$ A. I. Goldman, J. E. Shield, C. A. Guryan, and P. W. Stephens, in Proceedings of the 25th Anniversary Adriatico Research Conference on Quasicrystals (Ref. 8), p. 60.

${ }^{12}$ M. Audier and P. Guyot, in Proceedings of the 25th Anniversary Adriatico Research Conference on Quasicrystals (Ref. 8), p. 74.

${ }^{13}$ Pearson's Handbook of Crystallographic Data for Intermetallic Phases, P. Villars and L. D. Calvert (American Society for Metals, Metals Park, Ohio, 1986).

${ }^{14}$ J. Devaud-Rzepski, A. Quivy, Y. Calvayrac, M. CornierQuiquanuon, and D. Gratias, Philos. Mag. B 60, 855 (1989).

${ }^{15}$ J. E. Shield, L. S. Chumbley, A. I. Goldman, and R. W. McCallum (unpublished).

${ }^{16}$ K. Hiraga and M. Hirabayashi, J. Electron Micros. 36, 353 (1987).

${ }^{17}$ A. P. Tsai, H. S. Chen, A. Inoue, and T. Masumoto, Phys. Rev. B 43, 8782 (1991).

${ }^{18} \mathrm{~K}$. Sekimoto, in Quasicrystals, edited by T. Fujiwara and T. Ogawa (Springer-Verlag, Berlin, 1990), p. 120.

${ }^{19}$ Y. Ishii, in Quasicrystals (Ref. 18), p. 129. 


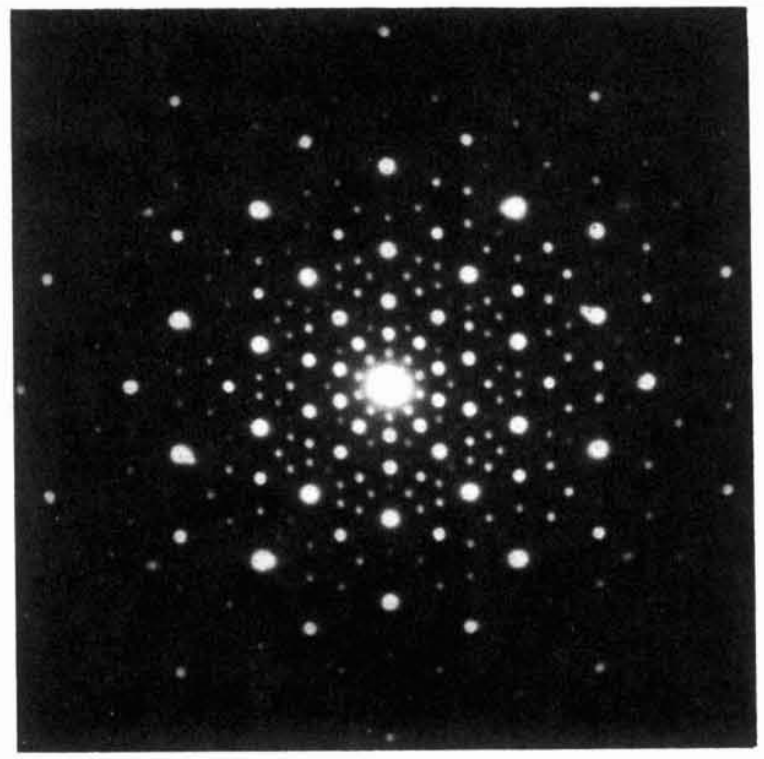

(a)

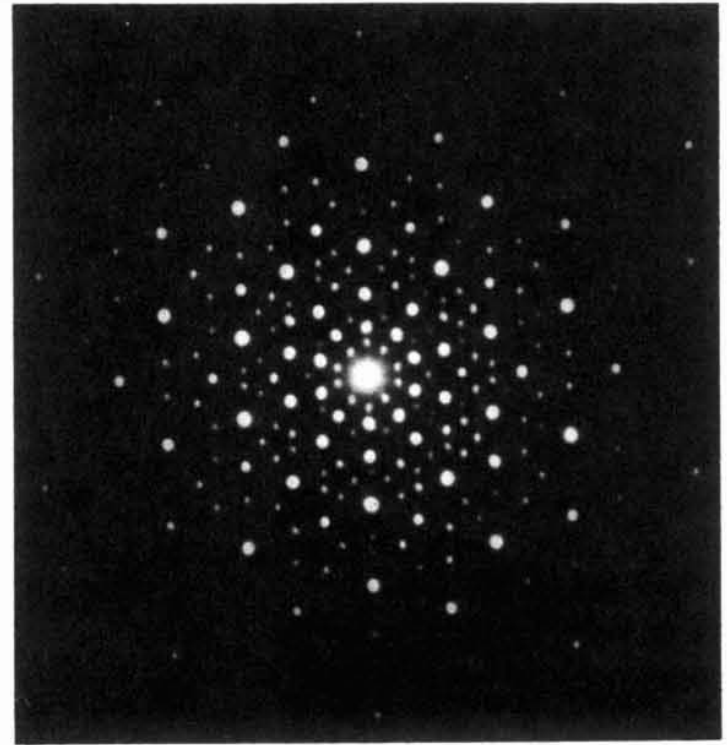

(b)

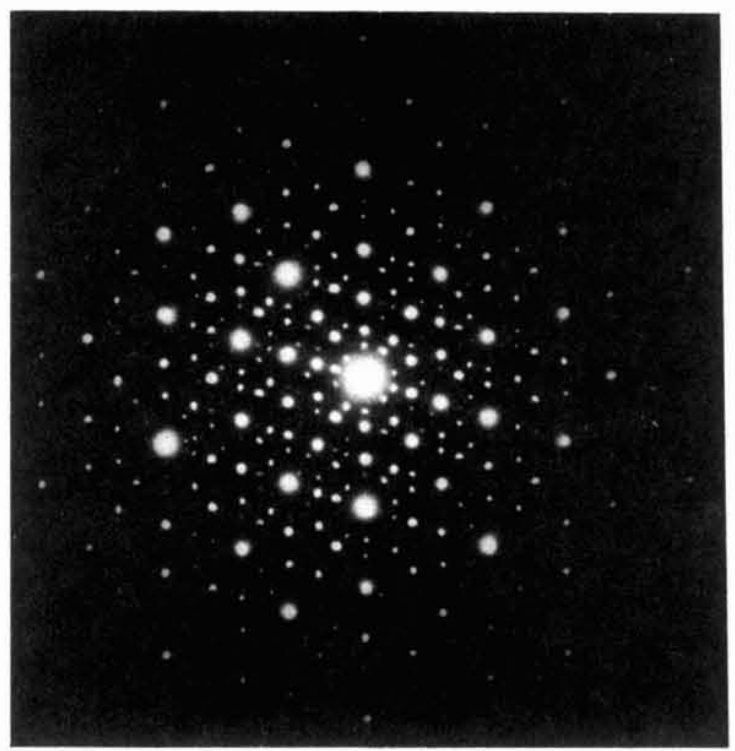

(c)

FIG. 10. SAD patterns of $\mathrm{Al}_{70} \mathrm{Cu}_{20} \mathrm{Ru}_{10}$ annealed at $800^{\circ} \mathrm{C}$ for (a) $48 \mathrm{~h}$ and (b) $7.5 \mathrm{~h}$. (c) $\mathrm{Al}_{65} \mathrm{Cu}_{20} \mathrm{Ru}_{15}$ annealed at $800^{\circ} \mathrm{C}$ for $1 \mathrm{~h}$, which is similar to (b). The deviations from perfect fivefold symmetry are evident in the latter patterns. 


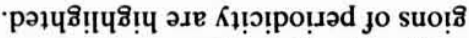
-ә IIEUS '(१)0I

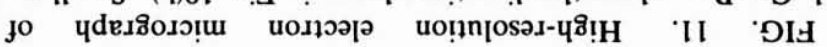

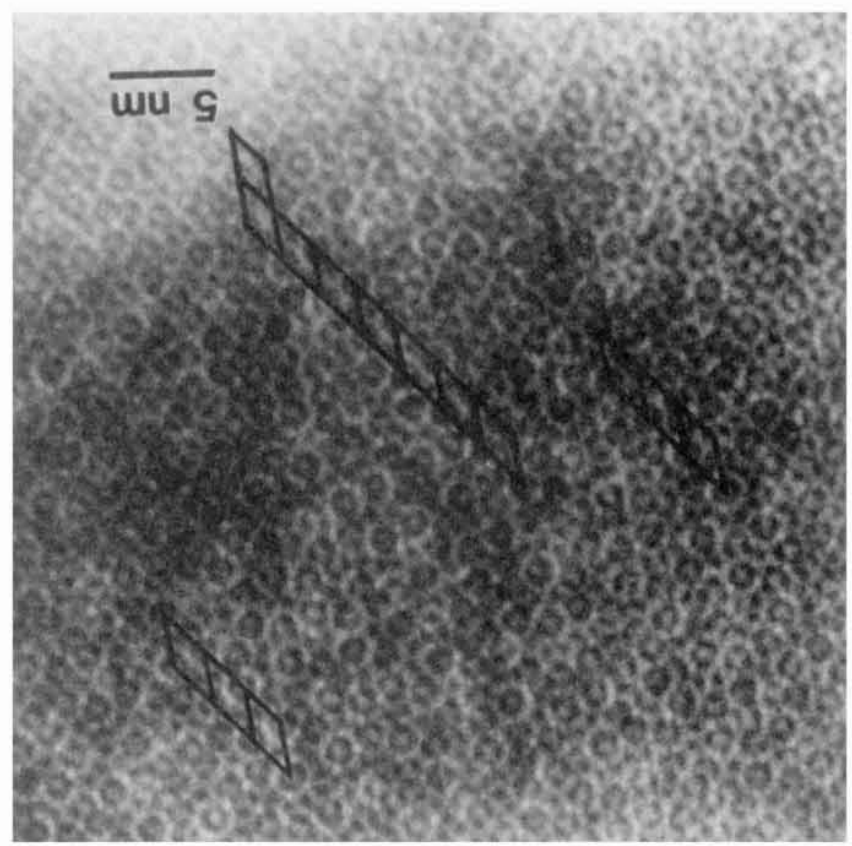




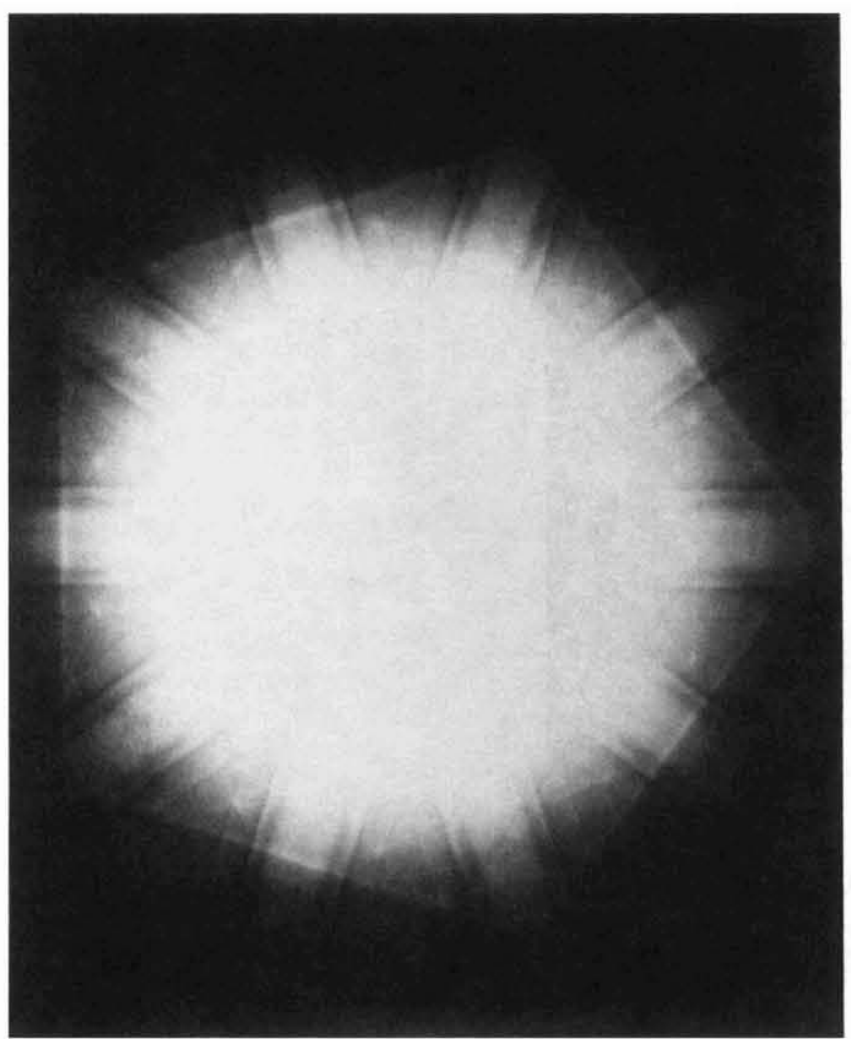

FIG. 12. Convergent beam electron diffraction (CBED) pattern of the fivefold axis shown in Figs. 10(b) and 11. The higher-order Laue zones (HOLZ) display fivefold symmetry. 


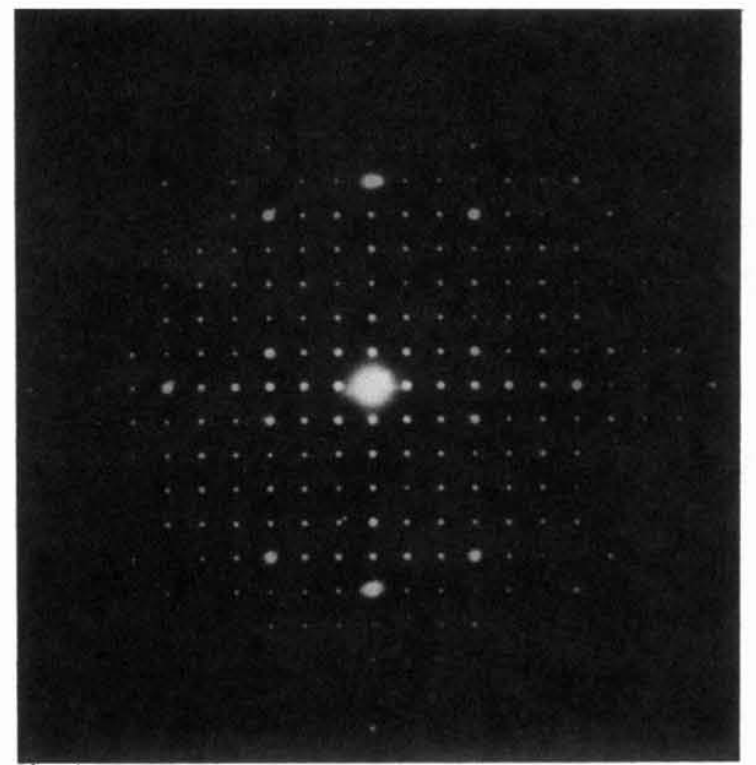

(a)

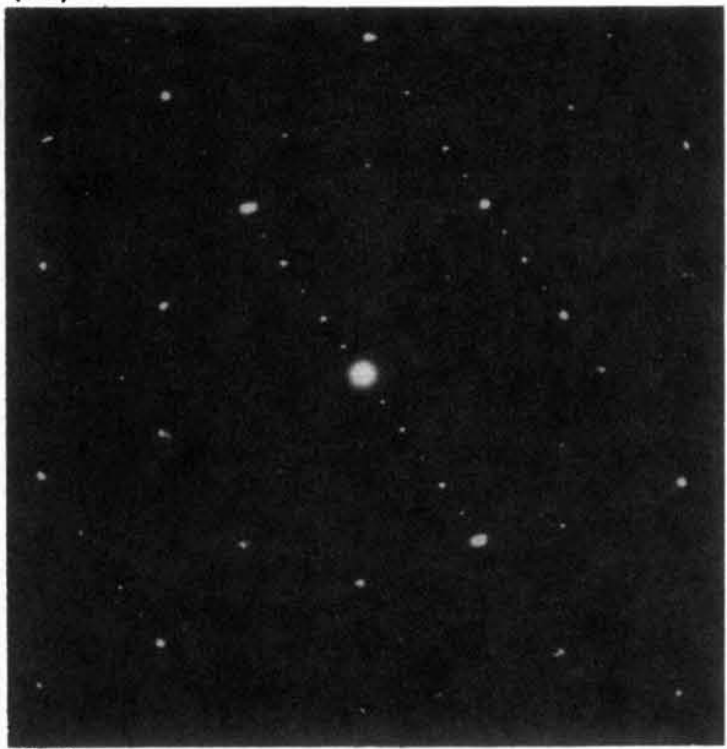

(b)

FIG. 14. SAD patterns of the cubic approximant phase along icosahedral (a) twofold and (b) fivefold directions. The directions within the cubic unit cell correspond to (a) $\langle 100\rangle$ and (b) irrational zone axes. 


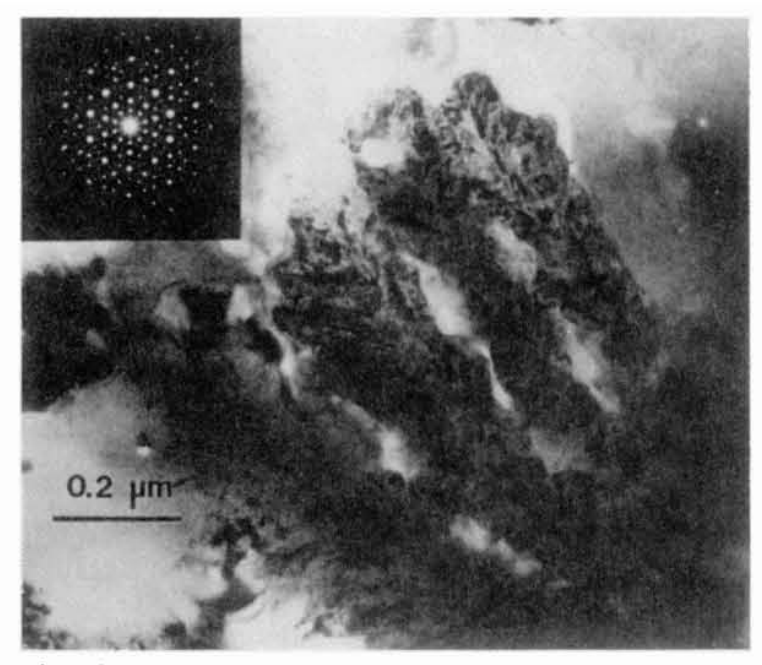

(a)

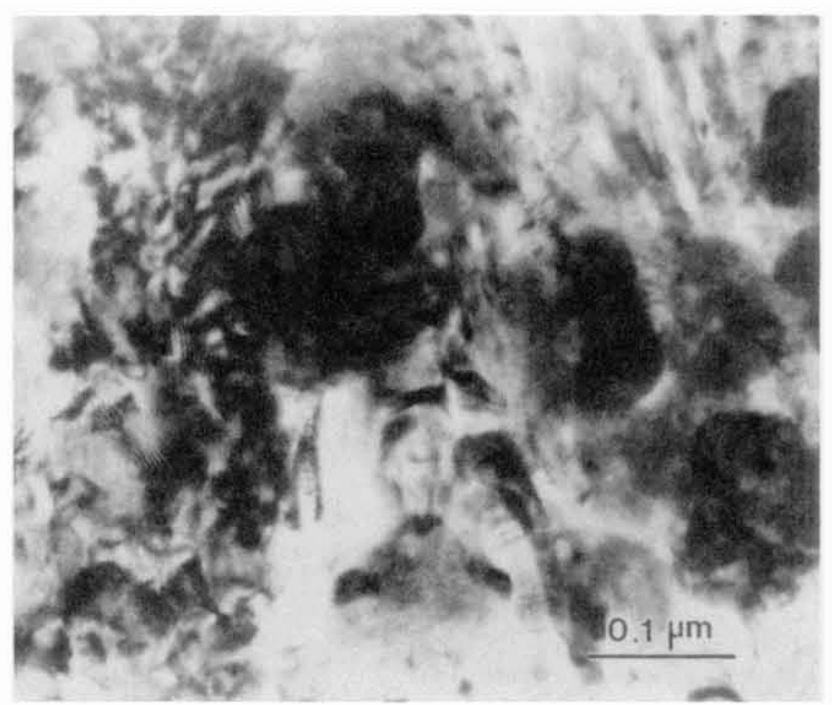

(b)

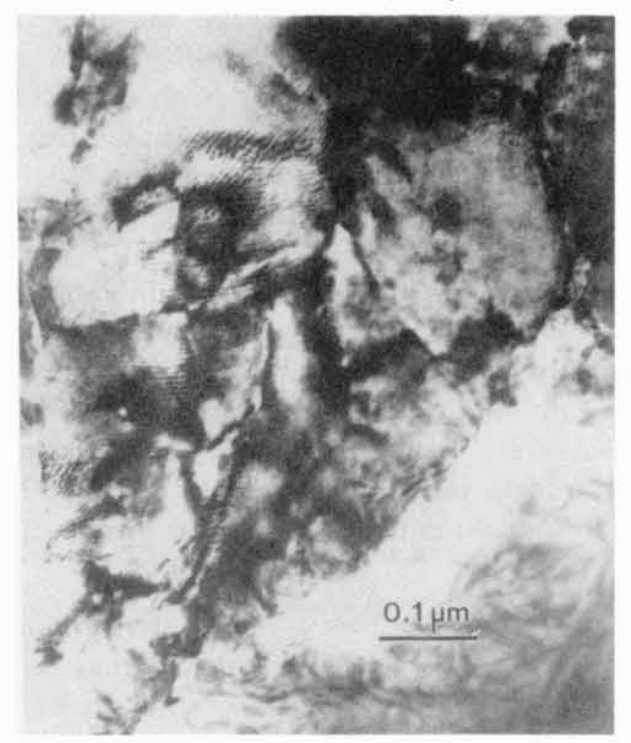

(c)

FIG. 3. Transmission electron micrographs of (a) $\mathrm{Al}_{65} \mathrm{Cu}_{23} \mathrm{Ru}_{12}$, which shows the dendritic icosahedral phase surrounded by the $\mathrm{Al}_{2} \mathrm{Cu}$ that forms peritectically (the five-fold diffraction pattern is shown in the inset); (b) $\mathrm{Al}_{75} \mathrm{Cu}_{20} \mathrm{Ru}_{5}$, with primary solidification of the icosahedral phase (left) and eutectic formation interdendritically (seen best in the upper right); and (c) $\mathrm{Al}_{70} \mathrm{Cu}_{15} \mathrm{Ru}_{15}, \mathrm{which}$ shows a more equiaxed morphology and does not contain the same contrast observed in the other samples (see text for more details). 